\title{
Schriftarten, Abkürzungen, Siglen und Zeichen in Texten Goethes, die im Kommentar gedruckt werden
}

\begin{tabular}{|c|c|}
\hline recte & Text Goethes \\
\hline Sperrung & Hervorhebung \\
\hline Sperrung & doppelte Hervorhebung \\
\hline grotesk & lateinische Schrift \\
\hline Sperrung & Hervorhebung in lateinischer Schrift \\
\hline Sperrung & doppelte Hervorhebung in lateinischer Schrift \\
\hline G? & zweifelhafte Eigenhändigkeit (bei Korrekturen) \\
\hline$x \times x$ & $\begin{array}{l}\text { unlesbare Buchstaben im Text Goethes und in den Varian- } \\
\text { ten }\end{array}$ \\
\hline abcd & unsichere Lesung im Text Goethes und in den Varianten \\
\hline$\langle$ abcd $\rangle$ & Zusätze des Editors im Text Goethes \\
\hline\langle\rangle & Textverlust der Vorlage im edierten Text \\
\hline$\ell$ & Abbrechungszeichen \\
\hline$\lceil\mathrm{abcd}\rceil$ & über der Zeile ergänzt \\
\hline$\lfloor$ abcd & unter der Zeile ergänzt \\
\hline$|\mathrm{abcd}|$ & in der Zeile ergänzt \\
\hline$\lceil\mathrm{abcd} \Gamma$ & am rechten Rand oder in der rechten Spalte ergänzt \\
\hline$\rceil$ abcd $\rceil$ & am linken Rand oder in der linken Spalte ergänzt \\
\hline$\downarrow$ abcd $\downarrow$ & am unteren Rand ergänzt \\
\hline & nachträgliche Trennung nach Zusammenschreibung \\
\hline$\cap$ & nachträgliche Zusammenschreibung \\
\hline$a b e d$ & gestrichen \\
\hline abed & Streichung in der Streichung \\
\hline abcd efgh & $\begin{array}{l}\text { Streichung vor der Niederschrift des folgenden Wortes oder } \\
\text { Zeichens (Sofortkorrektur) }\end{array}$ \\
\hline abcd efgh ijkl & später ersatzlos gestrichen (Tilgung) \\
\hline abcd & $\begin{array}{l}\text { Stützwort zur eindeutigen Zuordnung einer varianten } \\
\text { Textstelle }\end{array}$ \\
\hline gestr. & gestrichen \\
\hline $\mathrm{a} \mathbf{A}$ & a überschrieben durch $A$ oder korrigiert zu $A$ \\
\hline / & $\begin{array}{l}\text { Seitenwechsel in der Handschrift; Absatzzeichen in den Va- } \\
\text { rianten }\end{array}$ \\
\hline |:abcd:| & historische Klammerzeichen \\
\hline
\end{tabular}

